\title{
Conjugated Linoleic Acid and Cancer in Humans-Is there a Role or not? A Review of the Scientific Evidence
}

\author{
Michael N.I. Lokuruka \\ Department of Food Science and Nutrition \\ Karatina University, Box 1957-10101, Karatina, Kenya \\ e-mail: mlokuruka@gmail.com; mlokuruka@karu.ac.ke
}

https://doi.org/10.37512/300

\begin{abstract}
Conjugated linoleic acids are naturally occurring fatty acids that are found predominantly in ruminant meat, milk and dairy products. They are composed mainly of two isomers: cis-9, trans-11 and trans-10, cis-12 fatty acid. Their synthesis occurs mainly by the action of ruminal bacteria, Butyrivibrio Fibrisolvens, and a host of lactic acid bacteria, which isomerize linoleic acid to CLA or by synthesis via $\alpha 9$-desaturase of 11-trans octadecanoic acid, and, through desaturation of free linoleic acid or other unsaturated fatty acids. Although cis-9, trans-11 and trans-9, trans-11 CLA isomers have consistently shown anti-carcinogenicity on animal models and on cancerous human cells, results from clinical trials are inconclusive and conflicting. Despite most of the data on humans being mainly from epidemiological studies, a few clinical studies with breast and colorectal cancer sufferers have shown some promise. Controlled, long-term, racial and gender diverse, geographically spread clinical studies are required to understand the link between CLA intake and incidence of human cancers.
\end{abstract}

KEY WORDS: conjugated linoleic acid, cancer, link, humans

\section{INTRODUCTION}

Conjugated linoleic acids (CLAs) are a family of about 28 positional and geometric isomers of linoleic acid (LA) found mainly in meat, milk and dairy products derived from ruminants (Shokryazdan et al., 2015; Fuke \& Nornberg, 2016). CLAs can be either cis, cis or cis, trans or trans, trans-fatty acids, whose double bonds are conjugated and therefore separated by a single bond between them, instead of methylene interruption. They are composed of two main isomers: c9, t11 (cis-9, trans-11 fatty acid), which comprises about $80-90 \%$ of total conjugated linoleic acid (CLA) and t10, c12 (trans-10, cis-12 fatty acid), which comprises about 3-5\% of total CLA of foods that are good sources of the fatty acid (Wang \& Lee, 2013). There are also a few other types, but they have rarely been studied (Subbaiah et al., 2010).

The discovery of CLA and its health benefits came when Pariza et al. (1979) reported that grilled ground beef contained both bacterial mutagens and a substance that inhibited mutagenesis. The finding of mutagens in grilled beef was confirmatory, but evidence of a mutagenesis inhibitor was a novel discovery that had not been previously reported. Subsequently, Pariza and Hargraves (1985) established that the speculation that the mutagenic activity would inhibit carcinogenesis was indeed the case and $\mathrm{Ha}$ et al. (1987) identified the new anticarcinogen as conjugated linoleic acid.

Recognizing CLA's anti-cancer effects, the National Academy of Science's publication entitled "Carcinogens and Anti-carcinogens in the Human Diet" stated that "conjugated LA is the only fatty acid that has been shown unequivocally to inhibit carcinogenesis in experimental animals (National Research Council, 1996)." It went on to state that "much of the research to date has been with laboratory animal models, but CLA can reduce new tumor growth and destroy existing tumor cells. CLA has killed existing cancer cells in colon, ovarian and prostate carcinoma, leukemia, melanoma, and breast tumors". Also, CLA-enriched butter inhibited rat mammary tumor yield by $53 \%$, clearly showing the cis-9, trans-11 isomer was anti-carcinogenic". Thus 
the centrality of CLA in cancer research from then on was established.

LA, an omega-6 polyunsaturated, essential fatty acid, provides support, flexibility and integrity to cell membranes (Subbaiah et al., 2010). It is a naturally occurring trans saturated fatty acid that is found mainly in animal products-meat, milk and their derivative products from grass-fed animals (Nuernberg et al., 2005; Churruca, et al., 2009). When animals on pasture eat the omega-3 lipids in grass and other green plants, their gut flora convert the polyunsaturated fatty acids (PUFA) including LA into CLA. In milk, there's also an additional source-an enzyme in the cow's mammary gland that converts the fatty acid, vaccenic acid, into CLA (Banni et al., 2011). Although CLA is produced naturally and mainly in the digestive tract of ruminants such as cattle, goats, sheep, buffalo, it is also produced to a lesser degree in pigs, chickens and turkey ( $\mathrm{s}$, and the synthesis occurs mainly due to fermentative bacteria, Butyrivibrio Fibrisolvens, which isomerize LA to CLA or by synthesis via $\alpha 9$-desaturase of 11-trans octadecanoic acid by desaturation (Kishino et al., 2002). Other bacteria notably Lactobacillus strains (Lactobacillus acidophilus, Lactobacillus casei, Lactobacillus delbruechii, Lactobacillus paracasei, Lactobacillus pentosus, Lactobacillus plantarum, and Lactobacillus reuteri), Streptococcus salivarius, Bifidobacterium breve, Bifidobacterium dentium, and rumen bacteria (e.g., Butyrivibrio fibrisolvens) have been shown to have the ability to produce CLA from LA or other unsaturated, free fatty acids (Ogawa et al., 1998; Ogawa et al., 2001; Kishino et al., 2005; Macouzet et al., 2009).

Diet may influence CLA accumulation in the animal body and endogenous CLA production (Dhiman et al., 2005). Although it may be possible to increase CLA concentrations in animal tissues by increasing dietary CLA and other PUFAs in the animal diet, long-term CLA-supplemented feeding, may have an unfavourable cost-to-benefit ratio.

As many people eat meat from animals raised in factory farms, our diet is much lower in CLA as has been shown in laboratory analyses of diets in some parts of the World (Ip et al., 1994; Freitsche \& Steinhart, 1998; Aro et al., 2000; Rizenthaler et al., 2001), and yet any modern animal feeding practices would benefit human health if they raised the level of CLA in animal food products. In the USA, the average intake was $151 \mathrm{mg}$ /day for women and 212 for men (Ritzenthaler et al., 2001). The intake was 0.35 $\mathrm{mg}$ /day in women and $0.43 \mathrm{mg} /$ day in men in Germany (Freitsche \& Steinhart, 1998), $97.5 \mathrm{mg} /$ day in the UK (Mushtaq et al., 2010), and 310 and $90 \mathrm{mg} /$ day in adults with high and low dairy products consumption in Finland, respectively (Salminen, 1998). However, Aro (2000), estimated the intake in adult women to be higher at $132 \mathrm{mg} /$ day in Finland. Generally, these levels are much lower than the current level of 3-3.5 g/day that seems to confer health benefits in experimental animal models. It has been established in clinical trials that the dose of $3 \mathrm{~g} /$ day is relatively safe for humans such that the FDA of the US has conferred GRAS status on it (Benjamin et al., 2015). A dose of $\geq 6 \mathrm{~g} /$ day, has exhibited undesirable side effects including deposition of fat in the liver (van Wiljen, 2011), increased insulin resistance (Riserus et al., 2002), lowered HDL cholesterol and diarrhoea (Jadszus et al., 2010; van Wiljen, 2011).

CLA has been shown to be anti-carcinogenic (Banni et al., 2011), anti-obesity (Chin et al., 1994), and antidiabetic (Baumann, 1996), thus implying potential effectiveness in preventing lifestyle diseases. Also, reports suggest that physiological effects of CLA are different between the isomers, for example the $10 t, 12 \mathrm{c}$ isomer promoted mammary tumour growth and therefore raised the risk of breast cancer in overweight individuals with type 2 diabetes (Baumann, 1996), whereas the 9c,11t isomer was shown to be anti-carcinogenic (Banni et al., 1999; Beppu et al., 2007).

In this review, the anti-carcinogenicity of CLA and the possible mechanisms of action are discussed. However, most of the works discussed are on the rat, mice and hamsters. Although human clinical trials are increasingly being conducted, the few trials continue to yield conflicting and inconclusive results (Aro et al., 2000; Chajes et al., 2003; McCann et al., 2004; Chajes et al., 2009). This may in part be due to the small number of experiments, the difficulty experienced in obtaining accurate estimates of dietary CLA intake, studies being carried out in small populations and even if large, for short periods of time; small populations may lack the diversity in food habits (Benjamin et al., 2015). The chemical nature of the pure isomers that are often used in research may not also be in the form and proportions in which they exist in natural foods, where other biological agents may modulate their environment and actions. 


\section{CLA: SYNTHESIS, SOURCES AND EFFECTS OF PROCESSING}

The fat in beef contains about 1.7 to $10.8 \mathrm{mg}$ CLA/g of fat depending on the nature of the animal's diet, with 9-cis and 11-trans isomer predominating (Dhiman et al., 2005; Campbell et al., 2008). CLA is transferred naturally to meat, milk and dairy products through the lipids in food (Oliveira et al., 2008). In an experiment, Ogawa et al. (2005) established that due to the diversity of strains of lactic acid bacteria, the CLA produced comprised a mixture of cis-9, trans-11-octadecadienoic acid $(18: 2)$ and trans-9, trans-11-18:2. Lactobacillus plantarum AKU 1009a was a potentially good CLA producer, with the CLA production from LA reaching $40 \mathrm{mg} / \mathrm{ml}$ under the optimized conditions. The CLA-producing reaction was found to consist of two successive reactions-hydration of LA to 10hydroxy-12-octadecenoic acid and dehydrating isomerization of the hydroxy fatty acid to CLA. Based on these results, Lactic acid bacteria were found to transform ricinoleic acid (12-hydroxy-cis-9octadecenoic acid) to CLA (a mixture mainly of cis9, trans-11-18:2 and trans-9, trans-11-18:2). Castor oil, which is rich in the triacylglycerol form of ricinoleic acid, was found to act as a substrate for CLA production by lactic acid bacteria with the aid of lipase-catalyzed triacylglycerol hydrolysis. $L$. plantarum AKU 1009a produced conjugated trienoic fatty acids from alpha- and gamma-linolenic acid. The trienoic fatty acids produced from alphalinolenic acid were identified as cis-9, trans-11, cis15-octadecatrienoic acid (18:3) and trans-9, trans-11, cis-15-18:3, while those produced from gammalinolenic were cis-6, cis-9, trans-11-18:3 and cis-6, trans-9, trans-11-18:3.

CLA can be obtained by means of the enzyme $\alpha 9$ desaturase which promotes the desaturation of the 11 -trans octadecanoic acid (Griinari et al., 1997). Several different isomers of CLA including 11-trans and 9-cis are the best known because they are found in animal foods (Churruca et al., 2009), but a few others such as trans-9, trans-11 isomer are found predominantly in vegetable oils (Ecker et al., 2010). This later isomer has also been shown to have anticancer properties on human colon cancer cells (Beppu et al., 2007). It has also been shown that it is possible to obtain CLA in an industrial form, through the partial hydrogenation of linoleic acid or by thermal treatments, aiming to produce a compound with maximum biological activity and with a defined chemical composition (Blankson et al., 2000). However, the chemical forms which are often used as supplements may not have the proportion of isomers and the effectiveness of the natural CLA as found in foods (Chin et al., 1992; Bissonauth et al., 2006). In healthy humans, CLA and the related conjugated linolenic acid (CLNA) isomers are bioconverted from LA and alpha-linolenic acid, respectively, mainly by Bifidobacterium strains inhabiting the gastrointestinal tract (Nieuwenhove et al., 2007). However, this bioconversion may not occur at any significant level in those suffering from a digestive disease, gluten sensitivity, and/or dysbiosis, due to the reduced gut microbial populations (de Vrese \& Schrezenmeir, 2008).

Although food products from ruminants are the richest source of CLA (Fuke \& Nornberg, 2016), it is possible to enhance the CLA content of foods from non-ruminants by supplementing CLA with CLArich sources in their diets (Aydin, 2005; Bourre, 2005), but the effect ceases on removal of the supplementary feed source, thus underlining the importance of maintaining the natural sources of the fatty acid for optimal human nutrition. Chin et al. (1994) investigated the ability of non-ruminants (rats) to produce CLA. They supplemented the diet with $5 \%$ free linoleic acid or $8.6 \%$ corn oil (equivalent to $5 \%$ free LA as triglyceride) and observed higher tissue CLA concentrations in rats fed free LA than in control animals. These investigators concluded that the intestinal bacterial flora of rats can convert free LA, but not LA esterified in triglycerides, to cis, trans, C18:2 n-9, n-11 and trans, cis C18:2 n-9, n-11. The CLA content in milk, meat, or egg varies greatly from a low of $0.1 \%$ or less to a high of $2 \%$ or more of the milk, tissue, or egg yolk lipids, with milk lipids from ruminants having the highest concentrations. The CLA content in meat from ruminants is higher than in the meat of non-ruminants (e.g., $1.20 \%$ in lamb and $0.12 \%$ in pork). In the case of nonruminants, CLA may originate from dietary sources such as powdered meat and tallow (Freitsche \& Steinhart, 1998). A host of factors appear to affect the CLA content in milk, meat, and other food products from various species of animals, which could be broadly classified into diet, animal, and post-harvest related factors (Khanal \& Olson, 2004). 
Of all these factors, animal diet is the primary one and could be manipulated for enhancing the concentration of CLA in food products, both from ruminants and non-ruminants (Aydin, 2005). While animal-to-animal variation is also of great significance, post-harvest related factors appear to be of minor importance (Khanal \& Olson, 2004).

\section{Variability of CLA in Food Sources and Effect of Processing}

Food products from grass-fed ruminants are good sources of CLA and contain much more of it than those from grain-fed animals (Nuernberg et al., 2005), though consumers can obtain the same nutritional benefits from consuming high fat, grainfed food portions of the same products (Daley et al., 2010). It has been demonstrated that meat and dairy products from grass-fed animals can produce more CLA than those of cattle fed different supplementary diet ratios (Dhiman et al., 1999). Eggs from chicken that have been fed CLA and CLA-rich feeds are also rich in CLA (Suksombat et al., 2006). Interestingly, CLA in eggs has been shown to survive the temperatures encountered during frying, but in the presence of antioxidants (Ren et al., 2013), implying that the major route of destruction is likely to be oxidation. The CLA in milk and cheese heated by conventional processing methods is generally stable and may even be enhanced (Herzallah et al., 2005), while that in hard cheese is reduced proportionate with the severity of heating (Herzallah et al., 2006). Some mushrooms, such as the Agaricus bisporus and Agaricus subrufescens, are rare non-animal sources of CLA (Chen et al., 2006).

The average content of CLA found in milk samples from the Azores in Portugal varied from $1.45 \pm$ $0.21 \mathrm{mg} / \mathrm{g}$ fat in raw milk, $1.44 \pm 0.06 \mathrm{mg} / \mathrm{g}$ fat in thermized milk, and $1.40 \pm 0.11 \mathrm{mg} / \mathrm{g}$ fat in milk samples when pasteurized. The CLA varied between $9.6 \pm 0.5 \mathrm{mg} / \mathrm{g}$, in pasteurized cheeses and $10.8 \pm 4.2 \mathrm{mg} / \mathrm{g}$ in raw-milk cheeses (Kongo et al., 2014). These values agree with those reported by Pestana et al. (2009) and Regula et al. (2005) who reported that pasteurization, causes different changes in the free fatty acid profiles of ewes' milk, which in general has a higher content of CLA than cows' milk. However, Shantha et al. (1992) and Garcia-Lopez et al. (1994) reported that the application of heat enhanced the formation of linoleic acid radicals and increased CLA content during the production of natural and processed cheeses, though this may partly be contributed by the concentration of the solids content including lipid fractions as \% of serum (by dehydration through pressing and ripening under low relative humidity conditions). Although processing factors such as heating and ripening affect the CLA contents of a dairy product, the major source of its variation among products is the intrinsic amount of CLA present in the raw milk (Kongo et al., 2014), which varies with the livestock species (Pestana et al., 2009; Regula et al., 2005), as well as the nature of feed (Nuernberg et al., 2005). In a study in Argentina, Niuwenhove et al. (2008) found that CLA averaged 0.85 and 0.96 in milk and 0.76 and $1.04 \mathrm{~g} / 100 \mathrm{~g}$ of fatty acids in cheese of cow and goat, respectively, which seemed lower than values reported elsewhere (Ponnampalam et al., 2006). Cis-9, trans-11 was the major isomer present in both animal species in the Argentine study. In bovine raw milk, the CLA values vary from $0.2 \%$ to $3.7 \%$ of total milk fat, depending on animals' diet (Dhiman et al., 1999), its physiological state and season (Kelsey et al., 2003), with cheeses generally have much higher values than other dairy products (Shantha et al., 1992). The manner of processing of the cheese also influences the amount (Boylston et al., 1999). Milk from ruminants fed predominantly on pasture is known to be richer in CLA. Ponnampalam et al. (2006) reported higher values of CLA in milk and meat products from Australia and New Zealand than the equivalent products from elsewhere (Niuwenhove et al., 2008). This was attributed to the greater access to lush pasture, throughout the year by Australasian cattle. Similarly, in the Azores islands, where dairy cows are essentially pastured-fed all year round, Pestana et al. (2009), reported higher contents of CLA in milk as compared to similar milk and dairy products from mainland Portugal. Good fatty acid profiles were also established for cow and goat cheeses, from animals fed on natural pasture during spring and summer in Argentina (Nieuwenhove et al., 2009). The fat content of raw milk and species therefore largely determine the amount of CLA in derivative food products. 


\section{FUNDAMENTALS OF CANCER}

Cancer, an affliction that has over 100 different types, which are classified mainly by the type of body cell that is initially affected, is characterized by out-of-control cell growth (National Cancer Institute, 2018). Cancer harms the body when altered cells divide uncontrollably to form lumps or masses of tissue called tumours (except in leukemia, where cancer prohibits normal blood functioning by abnormal cell division in the blood stream). Tumours can grow and interfere with the digestive, nervous, and circulatory systems, and often release hormones that alter body function (Grundker \& Emons, 2017), especially when they metastasize and move round the body.

The WHO estimates that, worldwide, there were 14 million new cancer cases and 9.6 million cancerrelated deaths in 2018 (WHO, 2018), with 30\% of them from smoking, the probable cause of lung cancer, the leading cause of deaths from cancers worldwide. About $70 \%$ of global cancer-deaths occurred in low and middle income, and industrializing countries. The commonest cancer types globally are: anal, bladder, bone, breast, cervical, colon, colorectal, endometrial, kidney, leukemia, liver, lymp432homa, ovarian, pancreatic, prostate, stomach, thyroid, oesophageal, vaginal

\section{Cancer Risk Factors}

Cancer is ultimately the result of cells that uncontrollably grow and do not die, unlike normal cells in the body which follow an orderly path of growth, division, and death. Programmed cell death is called apoptosis, and when this process breaks down, cancer begins to form, leading to a mass of abnormal cells that grows out of control.

Cells can experience uncontrolled growth if there are mutations to DNA, and therefore, alterations to the genes involved in cell division. Four key types of genes are responsible for the cell division process: oncogenes tell cells when to divide, tumour suppressor genes tell cells when not to divide, suicide genes control apoptosis and instruct the cell to kill itself if something goes wrong, and DNA-repair genes instruct a cell to repair damaged DNA. Cancer occurs when a cell's gene mutations make the cell unable to correct DNA damage and and vulvar cancer, but not in the order of prevalence (WHO, 2018). Currently lung, stomach, liver, colon and breast cancer cause the most cancer-deaths each year globally $(\mathrm{MoH}, 2013)$. In the past, cancer has received low priority in healthcare services in SubSaharan Africa, the reason partly being the undoubtedly overwhelming burden of communicable diseases. In Kenya, cancer is the $3^{\text {rd }}$ most prevalent cause of death (after infectious diseases and cardiovascular disease) and accounts for an estimated 22,000 deaths annually, out of a reported prevalence rate of 28,000 cases annually, though increasing prevalence is evident $(\mathrm{MoH}, 2013)$. The commonest types of cancers in Kenya are oesophageal, prostate and Kaposi in men, while breast, oesophageal and cervical cancer are common in women, in declining order of prevalence in those affected, reported to medical facilities and diagnosed appropriately (MoPHS \& MoMS, 2013). Cancer is responsible for $7 \%$ of the total national mortality each year in Kenya (MoH, 2013).

Cancer results from internal and external risk factors working together and/or in sequence to trigger the affliction. People may be exposed to risk factors or cancer-causing agents in their environment and/or from their lifestyles. unable to commit suicide. Also, cancer is a result of mutations often due to carcinogens that inhibit oncogene and tumour suppressor gene function, leading to uncontrollable cell growth.

Carcinogens are directly responsible for damaging DNA, promoting or aiding cancer. Tobacco, asbestos, arsenic, radiation such as gamma and $\mathrm{x}$-rays, exposure to excessive ultraviolet (UV) radiation from the sun, and a host of lab chemicals are all examples of carcinogens (American Cancer Society, 2019). When our bodies are exposed to carcinogens, free radicals affect the body's ability to function normally.

Cancer seems also to be the result of a genetic predisposition that is inherited from family members (American Cancer Society-ACS, 2019). It is possible to be born with certain genetic mutations or a fault in a gene that makes one statistically more likely to 
develop cancer later in life.

As we age, there is an increase in the number of possible cancer-causing mutations in our DNA (WHO, 2018). This potential makes age an important risk factor for cancer. Several viruses have also been linked to cancer including: human papillomavirus (a cause of cervical cancer), hepatitis $\mathrm{B}$ and $\mathrm{C}$ (causes of liver cancer), and Epstein-Barr virus (a cause of some childhood cancers) (ACS, 2019). Human immunodeficiency virus (HIV)-and anything else that suppresses or weakens the immune system, inhibits the body's ability to fight infections and increases the chance of developing cancer (ACS, 2019), as it is for many other ailments. Other risk factors that predispose one to cancer include: inactivity, race (related to DNA and heredity), pollution (chemical carcinogens), inappropriate diet, chemicals from other sources other than pollution.

The WHO's International Agency for Research on Cancer (IARC) has now placed dirty air in the same category of carcinogens such as tobacco smoke, ultraviolet radiation and plutonium (WHO, 2018). IARC estimates that about 223,000 lung cancer deaths globally, can be blamed on exposure to air pollution (WHO, 2018).

However, experts estimate that at least a third of adult cancer cases are linked to lifestyle (National Cancer Institute, 2018), which is within one's control. It would therefore follow that with every healthy choice one makes, and every unhealthy habit one drops, cancer risk drops. Eight factors that are regarded as the healthiest habits that one can develop to help prevent cancer include: staying tobacco-free, maintaining an appropriate body mass index, increasing the proportion of plant foods in diets, cessation of alcohol abuse, planned and frequent screening, daily physical activity, shaking off stress, and heredity. In relation to food, certain bioactive compounds including CLA, have been linked mainly in causal studies on animal models to the reduction or at the best, prevention of cancer initiation.

\section{POTENTIAL ROLE OF FOODS IN CANCER PREVENTION}

Although several cancers are influenced by lifestyle, delaying or preventing disease onset seems to be considerably influenced by diet (Donaldson, 2004), and more so by diets in which fruits, vegetable foods (Freudenheim et al., 1996) and CLA (Ip et al., 1994) are significant components. However, other studies have not established any positive or strong inverse correlation between fruit, dietary fibre, vegetable intake or the specific vitamins (A, C, E) and/or supplements or food and supplements considered together and the risk of cancer initiation or prevention (Kushi et al., 1996; Fairfield et al., 2001; Botterweck et al., 2000) and yet the encouraging results of the anticancer effects of CLA in animal models (Ip et al., 1994; Ip et al., 1999; Banni et al., 2001), have over the last few years stimulated further investigations through human clinical trials.

Research has generally shown that fruits and vegetables contain a variety of bioactive compounds (Singh et al., 2016). These include insoluble fibre, a variety of polyphenols, organic acids, etc. with the level of antioxidant activity (measured by ABTS- 2,2'-azino-bis(3ethylbenzthiazoline-6-sulphonic acid)) and DPPH2,2-diphenyl-1- picrylhydrazyl) being indicative of bioactivity. Gallic acid, protocatechuic acid, catechins, caffeic acid, ferulic acid, sinapic acid, quercetin, resveratrol and kaempferol are detectable in different fruits and vegetables, with fruit peels also having high antioxidant activity and therefore promising as valuable sources of minerals and polyphenols (Singh et al., 2016). In a UK study, Proteggente et al. (2002), showed that fruits and vegetables that appeared to be rich in anthocyanins (e.g. strawberry, raspberry and red plum) demonstrated the highest antioxidant activities, followed by those rich in flavanones (e.g. orange and grapefruit) and flavonols (e.g. onion, leek, spinach and green cabbage), while the hydroxycinnamate-rich fruit (e.g. apple, tomato, pear and peach) consistently elicited the lower antioxidant activities. The antioxidant capacities of aqueous/methanolic extracts were comparatively assessed using the TEAC (Trolox Equivalent Antioxidant Capacity), the FRAP (Ferric Reducing Ability of Plasma) and ORAC (Oxygen Radical Absorbance Capacity) assays, 
which comprise contributions from polyphenols, simple phenols and the ascorbate component. The TEAC, FRAP and ORAC values for each extract were shown to be relatively similar and wellcorrelated with the total phenolic and vitamin $\mathrm{C}$ contents (Proteggente al., 2002). The same study established that the antioxidant activities (expressed as TEAC) in terms of $100 \mathrm{~g}$ fresh weight uncooked portion size were in the order: strawberry $>>$ raspberry $=$ red plum $>>$ red cabbage $>>>$ grapefruit $=$ orange $>$ spinach $>$ broccoli $>$ green grape approximately $/=$ onion $>$ green cabbage $>$ pea $>$ apple $>$ cauliflower tomato approximately/= peach $=$ leek $>$ banana approximately/= lettuce. In an earlier study, Paganga et al. (1999) showed that the major phenolic antioxidant components of eggplant were chlorogenic acid in the flesh and a delphinidin conjugate in the skin. In the case of apple, the major phenolic antioxidants detected were chlorogenic acid, procyanidins/catechin compounds, rutin and phloridzin, while quercetin glycosides were the major phenolic components of onion. The highly significant correlation between consumption of fats and oils and death rates from leukemia and malignant neoplasia of the breast, ovaries, and rectum among persons over 55 years of age seemed to reflect greater lipid peroxidation (Lea, 1966). Studies on atherosclerosis reveal the probability that the disease may be due to free radical reactions involving diet-derived lipids in the arterial wall and serum to yield peroxides and other substances. These compounds induce endothelial cell injury and produce changes in the arterial walls (Harman, 1992). Brown and Rice-Evans (1998) found that luteolin-rich artichoke extract protected low-density lipoprotein from oxidation in vitro. In two reviews, Devasagayam et al. (2004) and Dillard and German (2000) discuss the beneficial effects of antioxidants and nutraceuticals in disease prevention. Weisburger (1999), concluded that most chronic diseases, including coronary heart disease and many types of cancer depend on the in vivo conversion of cellular macromolecules or of carcinogens to specific reactive, oxidized forms. Therefore, health promoting nutrition recommends the daily intake of five to ten servings of vegetables and fruits, fruit juices, red wine and tea which are rich sources of micronutrients with antioxidant properties, including the antioxidant vitamins $\mathrm{C}, \mathrm{E}$ and beta-carotene. While tomatoes contain lycopene, a stable, active antioxidant, many vegetables contain quercetin and related polyphenolic compounds. Green tea is a source of epigallocatechin gallate, while black tea is associated with theaflavin and the associated thearubigins (Lin et al., 1998). Red wine contains resveratrol (Das et al., 1999), while ruminant meats, milk and dairy products contain CLA (Bolylston et al., 1995). The diverse antioxidants in foods, red wine and tea provide the necessary antioxidant resources for the body to control oxidation reactions in the body, which if not controlled would result in possible adverse health consequences. For example, the oxidation of LDL cholesterol yields a product that damages the vascular system (Harman, 1992). Cancers of the stomach seem to be caused by the consumption of salted, pickled foods yielding direct-acting carcinogens, whose formation is inhibited by the antioxidant vitamins C and E (Glatthaar et al., 1986; Rock et al., 1996). Cancer in the colon, breast, prostate and pancreas may be caused by a new class of carcinogens, the heterocyclic amines (Grieswold et al., 1968; Butler et al., 2003), formed during the broiling or frying of creatininecontaining foods, including fish and meats. Their formation and action was shown to be inhibited by antioxidants in soy, tea, vitamin $\mathrm{C}$ and by the synthetic antioxidants BHA and BHT (Chung, 1999; Rock et al., 1996). The growth, proliferation and development of abnormal preneoplastic and neoplastic cells also involves oxidation reactions, including the formation of active oxygen or peroxy compounds (Lea, 1966). Such reactions were found to be inhibited by antioxidants in tea, tomatoes or vegetables (Weisburger, 1999). CLA has been shown to prevent cancer in animal models and cancerous human cell lines (Ip et al., 1991, 1994, 1999; Banni et al., 2001). 
Very few clinical studies have been conducted to relate CLA consumption with the incidence of different cancer types, as the data available is mainly from epidemiological studies. However, many researchers have recently focused on human breast and colorectal cancer; in an elaborate followup study using Cox proportional hazards models, Larsson et al. (2009) showed that the dietary intake of CLA showed no evidence for a protective role against breast cancer development in women. Also, Chajes et al. (2002) conducted a case-control study among 297 women treated for breast cancer or benign breast disease to evaluate the hypothesis that CLA protects against breast cancer. They could not show a link for the negative association between adipose tissue CLA (predominantly 9CLA) and the risk of breast cancer. However, highfat dairy food and CLA intake were examined in 60,708 women of age 40 to 76 (the Swedish Mammography Cohort Study) with 14.8-year follow-up. It was found that women who consumed four or more servings of high-fat dairy foods daily (including whole milk, full-fat cultured milk, cheese, cream, sour cream and butter) showed half the risk of developing colorectal cancer, compared to women who consumed less than two servings per day (Larsson et al., 2005). The study established that the consumption of CLA was associated with an almost 30 percent reduction in the risk of colorectal cancer. In another study (the Western New York Exposures and Breast Cancer Study, WEB), McCann et al. (2004) demonstrated that although there was no clear protective effect of 9CLA in premenopausal or postmenopausal women with a higher intake, i.e., the number of oestrogen receptor (ER)-negative cells to ER-positive cells, the ratios decreased in the premenopausal women in the higher quartile. The authors concluded that, although CLA intake was not related to overall breast cancer risk, there may be associations with tumor biology at least among premenopausal women. But another epidemiological study (the Netherlands Cohort Study) with 6.4-yr of follow-up evaluated the relationship between the intakes of CLA and other fatty acids. The study failed to confirm the anticarcinogenic property of CLA in humans with breast cancer incidence (Brown, 2008). A study by Aro et al. (2000) examined the relationship between dietary or serum CLA in women and the risk of breast cancer. The study found an inverse association between dietary and serum CLA and risk of breast cancer in postmenopausal women. But in contrast, the adipose tissue extracts from a population of French patients with invasive breast carcinoma, failed to reveal any positive correlation between adipose tissue CLA and the incidence of breast cancer (Chajes et al., 2003). A study by Hoffmann et al. (2006), examined the polyunsaturated fatty acid profile of healthy renal tissue and cancerous renal parts. Although it revealed differences in CLA content, the design of the experiment could not reveal the role of CLA in renal carcinoma. In conclusion, the available human clinical studies are conflicting and have not convincingly established the anti-cancer property of CLA.

\section{PROBABLE MECHANISMS OF ACTION OF CLA IN CANCER PREVENTION}

It seems likely that CLA exerts inhibitory properties in carcinogenesis via one or more pathways with some tissue specificity. A study by Agatha et al. (2004), showed that CLA isomers are converted by the leukemia cells into conjugated diene fatty acids as linoleic acid into nonconjugated PUFAs. The growth inhibitory effects of CLA (with 30-120 microM) on leukemia cells were dependent upon the type and concentration of CLA isomers present. CLA-supplemented cells with low concentrations $(<60$ microM) were not sufficient to impair cell proliferation. Nevertheless, higher amounts of CLAs ( $>60$ microM) had the
CLA type dependent anti-proliferative effects. The authors thus concluded that the 9 cis, 11 trans- and the 9 cis, 11 cis-CLA isomers regulate cell growth and survival in different leukemia cell types through their existence alone and/or by their inhibitory effects of desaturase activity. A study by Beppu et al. (2006), compared the growth inhibitory effects of pure CLA isomers cis 9, cis 11-CLA, c9, t11-CLA, t9, t11CLA, and t10, c12-CLA on human colon cancer cell lines (Caco-2, HT-29 and DLD-1). The strongest inhibitory effect was shown by $\mathrm{t} 9$, t11-CLA, followed by t10, c12-CLA, c9, c11-CLA and c9, t11CLA, respectively. The order of the inhibitory effect 
of CLA isomer was confirmed in the presence of $1 \%$ FBS. CLA isomers supplemented in the culture medium were readily incorporated into the cellular lipids of Caco-2 and changed their fatty acid composition. The CLA contents in cellular lipids were $26.2+/-2.7 \%$ for $\mathrm{t} 9$, t11-CLA, $35.9+/-0.3 \%$ for c9, t11-CLA and $46.3+/-0.8 \%$ for $\mathrm{t} 10$, c12-CLA, respectively. DNA fragmentation was clearly recognized in Caco-2 cells treated with t9, t11-CLA. This apoptotic effect of t9, t11-CLA was dose- and time-dependent. DNA fragmentation was also induced by 9c,11t-CLA and t10, c12-CLA. However, fragmentation levels with both isomers were much lower than that with $\mathrm{t} 9$, t11-CLA. t9, t11-CLA treatment of Caco-2 cells decreased Bcl-2 levels in association with apoptosis, but Bax levels remained unchanged. These results suggest that decreased expression of Bcl-2 by $\mathrm{t}$, t11-CLA might increase the sensitivity of cells to lipid peroxidation and to programmed cell death, apoptosis. In another study, Huang et al. (2007), investigated the antiproliferative effects of two isomers of CLA (c9, t11CLA; $\mathrm{t}$, $\mathrm{t} 11$-CLA) and their mixture on the human colon adenocarcinoma cell line Caco-2, incubated in serum-free medium. The anti-proliferative effects of different concentrations $(0,25,50,100,200$ micromol/L) of linoleic acid, c9, t11-CLA, t9, t11CLA (the purity of LA and CLA was $96 \%$ ) and a mixture of $\mathrm{c} 9, \mathrm{t} 11-\mathrm{CLA}$ and $\mathrm{t} 9, \mathrm{t} 11-\mathrm{CLA}(1: 1 \mathrm{v} / \mathrm{v})$ on caco-2 in various action time $(1 \mathrm{~d}, 2 \mathrm{~d}, 3 \mathrm{~d}, 4 \mathrm{~d})$ were tested in the study. The anti-proliferative effects of the four substances in the same concentration and with the same action time were compared. All substances tested could inhibit Caco-2 cell proliferation. The higher anti-proliferative activity in the four materials was: the mixture of CLA, then $\mathrm{t}$, t11-CLA, c9, t11-CLA, and linoleic acid, respectively. The activity was closely related to treatment time and concentration. The authors concluded that the isomer t9, t11-CLA has considerable anti-proliferative activity. Mechanisms of inhibition of carcinogenesis therefore include reduction of cell proliferation, alterations in the components of the cell cycle and induction of apoptosis (Belury et al., 2002; Miller et al., 2003). In addition, CLA modulates markers of immunity and eicosanoid formation as well as lipid metabolism and gene expression (Yamasaki et al., 2000; O'Shea et al., 2004).

isomers. As most research work to the present has been done with animal models, and whatever work has been done on humans has mainly been of epidemiological nature, more clinical trials on humans need to be undertaken to establish the benefits of CLA in cancer prevention, as the few clinical trials have given conflicting and therefore inconclusive results. It is thus imperative that controlled studies be carried out with large populations of different gender and racial groups, of diverse dietary habits and in different geographical locations. Future research should also seek to establish methods for controlling the amount of CLA and CLA isomers in animal products and to determine the CLA amount that must be consumed to improve human health.

and mechanism of action for different CLA 


\section{REFERENCES}

Agatha, G., Voigt, A., Kauf, E. \& Zint, F. (2004). Conjugated linoleic acid modulation of cell membrane in leukemia cells. Cancer Lett. 209(1), 87-103.

American Cancer Society (ACS). Known and probable carcinogens. Found at: www.cancer.org/cancer/ cancer-causes/general-info/known-and-probable-human-carcinogens.html. Accessed $11^{\text {th }}$ April 2019.

(Lausanne); 8, 187. DOI: 10.3389/fendo 2017.00189.ecollection 2017.

Aro, AS., Mannisto, I., Salminen, ML., V. Kataja \& Uusitupa. M. (2000). Inverse association between die tary and serum conjugated linoleic acid and risk of breast cancer in postmenopausal women. Nutri tion in Cancer 38, 151-157.

Banni, Sebastanao., Elisabetta Angioni, Viviana Casu, Maria Paola, Melis Gianfranca Carta, Francesco, P. Corongiu Henry Thompson, \& Ip Clement. (1999). Decrease in linoleic acid metabolites as a poten tial mechanism in cancer risk reduction by conjugated linoleic acid. Carcinogenesis 20(6), 10191024. https://doi.org/10.1093/carcin/20.6.1019. Accessed on $25^{\text {th }}$ Nov 2018.

Banni, Sebastiano., Elisabetta Angioni, Elisabetta Murru, Gianfranca Carta, Maria Paola Melis, \& Dale Bauman. (2001). Vaccenic Acid Feeding Increases Tissue Levels of Conjugated Linoleic Acid and Suppresses Development of Premalignant Lesions in Rat Mammary Gland. Journal of Nutrition and Cancer 41(1-2), 91-97.

Blankson, H., Stakkestad, JA., Fagertun, H., Thom, E., Wadstein, J. \& Gudmundsen, O. (2000). Conjugated linoleic acid reduces body fat mass in overweight and obese humans. J. Nutr. 130, 2943-8. Accessed on $2^{\text {nd }}$ October, 2018.

Belury, MA. (2002). Inhibition of carcinogenesis by conjugated linoleic acid: potential mechanisms of ac tion. J. Nutr. 132(10), 2995-8.

Beppu, F., Hosokawa, M., Tanaka, L., Kohno, H., Tanaka, T. \& Miyashita, K. (2006). Potent inhibitory ef fect of trans9, trans11 isomer of conjugated linoleic acid on the growth of human colon cancer cells. Journal of Nutritional Biochemistry 17(12), 830-6.

Beppu, F., Hosokawa, M., Leo, T. \& Kohno, H. (2007). Potent inhibitory effect of trans9, trans11 isomer of conjugated linoleic acid on the growth of human colon cancer cells. Journal of Nutritional Biochem istry $17(12), 830-836$.

Bissonauth, V., Chouinnard, Y., Marin, J., N. Leblanc, D. Richard \& Jacques, H. (2006). The effects of t10, c12 CLA isomer compared with c9, t11 CLA isomer on lipid metabolism and body composition in hamsters. Journal of Nutritional Biochemistry 17(9), 559-603.

Botterweck, A.A., van den Brandt, P.A. \& Goldbohm, R.A. (2000). Vitamins, carotenoids, dietary fiber and the risk of gastric carcinoma: results from a prospective study after 6.3 years of follow-up. Cancer 88 (4), 737-48.

Bourre, J.M. (2005). Where to find omega-3 fatty acids and how feeding animals with diet enriched in ome ga-3 fatty acids to increase nutritional value of derived products for human: what is useful? Journal of Nutrition in Health and Aging 9(4), 232-42.

Boylston, H.L., Luedecke, L.O. \& Shultz, T.D. (1999). Conjugated Linoleic Acid content of cheddar-type cheeses as affected by processing. Journal of Food Science 64, 874-878.

Brown, A. (2008). Thesis title: selected measures of health on women fed conjugated linoleic acid-enriched from organic, pasture-fed cattle. Iowa, Iowa State University; p 88-99.

Brown. J.E. \& Rice-Evans, C.A. (1998). Luteolin-rich artichoke extract protects low density lipoprotein from oxidation in vitro. Free Radical Research 29, 247-255.

Butler, L.M., Sinha, R., Millikan, R.C., Martin, C.F., Newman, B., Gammon, B.M.D., Ammerman, A.S. \& Sandler, R.S. (2003). Heterocyclic amines, meat intake, and association with colon cancer in a populationbased study. American Journal of Epidemiology 157 (5), 434-445. https://doi.org/10.1093/aje/kwf221. Accessed on $8^{\text {th }}$ December, 2018. 
Campbell, B. \& Kreider, R. (2008). Conjugated linoleic acids. Curr Sports Med Rep. 7, 237-41. DOI: 10.1249/JSR.0b013e31817f2aab. Accessed on $5^{\text {th }}$ October, 2018.

Chages, V., Lavillonniere, F., Ferrari, P., Jordan, ML., Pinault. L. \& Maillard, V et al. (2002). Conjugated lin oleic acid content in breast adipose tissue is not associated with the relative risk of breast cancer in a population of French patients. Cancer Epidemiol BioMar Prev. 11(7), 672-73.

Chen, S., Sei-Ryang, Oh., Pung, S., Hur, G., Ye, J.J., Kwok, S.L., Shrode, GE., Belury. M., Adams, L.S \& Williams, D. (2006). Anti-aromatase activity of phytochemicals in white button mushrooms (Agaricus bisporus). Cancer Research 66, 12026-12034.

Chin, S.F., Storkson, J.M., Albright, K.J., Cook, M.E. \& Pariza, M.W. (1994). Conjugated linoleic Acid is a growth factor for rats as shown by enhanced weight gain and improved feed efficiency. Journal of $\mathrm{Nu}$ trition 124, 2344-2349.

Chin, S.F., Kiu, W., Storkson, J.M., Ha, Y.L \& Pariza, M.W. (1992). Dietary sources of conjugated dienoic acid isomers of linoleic acid -a newly recognized class of anticarcinogens. Journal of Food Composi tion and Analysis 5(3), 185-197.

Chung, J.G. (1999). Effects of butylated hydroxyanisole (BHA) and butylated hydroxytoluene (BHT) on the acetylation of 2-aminofluorene and DNA-2-aminofluorene adducts in the rat. Toxicological Sciences 51(2), 202-10.

Churruca, I., Fernandez-Quintela, A. \& Portillo, MP. (2009). Conjugated linoleic acid isomers: differences in metabolism and biological effects. Biofactors 35, 105-11. doi: 10.1002/biof.13. Accessed on $6^{\text {th }}$ No vember, 2018.

Dacombe, F.C. \& Rice-Evans, CA. (2002). The antioxidant activity of regularly consumed fruit and vegetables reflects their phenolic and vitamin C composition. Free Radical Research 36(2), 217-33.

Das, DK., Sato, M., Ray, PS., Maulik, G., Engelman, RM., Bertelli, AA \& Bertelli, A. (1999). Cardioprotec tion of red wine: role of polyphenolic antioxidants. Experimental_Gerontology 34(3), 293-303.

Daley, Cynthia A., Amber Abbott., Patrick S Doyle., Glenn A Nader \& Stephanie Larson. (2010). A review of fatty acid profiles and antioxidant content in grass-fed and grain-fed beef. Nutrition Journal 9,10.

Found at: https://doi.org/10.1186/1475-2891-9-10. Accessed $22^{\text {nd }}$ October, 2018.

Devasagayam, T.P., Tilak, J.C., Boloor, K.K., Sane, K.S., Ghaskadbi, S.S \& Lele, R.D. (2004). Free radicals and antioxidants in Human Health: Current status and future prospects. Journal of the Association of Physicians of India 52, 794-803.

Dhiman, T.R., Anand, G.R., Satter, L.D. \& Pariza, M.W. (1999). Conjugated linoleic acid content of milk from cows fed different diets. Journal of Dairy Science 82(10), 2146-56. Found at: https:// doi.org/10.3168/jds.2010-3803. Accessed on $22^{\text {nd }}$ October 2018.

Dhiman, T.R., Nam, SH. \& Ure, A.L. (2005). Factors affecting conjugated linoleic acid content in milk and meat. Critical Reviews in Food Science and Nutrition 45(6), 463-82.

Donaldson, Michael S. (2004). Nutrition and cancer: A review of the evidence for an anti-cancer diet; Cancer 3, 19. doi: 10.1186/1475-2891-3-19.

Ecker, JL., Liebisch, G., Scherer, M. \& Schmitz, G. (2010). Differential effects of conjugated linoleic acid iso mers on macrophage glycerophospholipid metabolism. J. of Lipid Research 51(9), 2686-94. doi: 10.1194/jlr.M007906. Accessed on $15^{\text {th }}$ Oct 2018.

Fairfield, K.M., Hankinson, SE., Rosner, B.A., Hunter, D.J., Colditz, G.A \& Willett, W.C. (2001). Risk of ovarian carcinoma and consumption of vitamins $\mathrm{A}, \mathrm{C}$, and $\mathrm{E}$ and specific carotenoids: a prospective analysis. Cancer 92(9), 2318-26.

Fritsche, J. \& Steinhardt, H. (1998). Analysis, occurrence, and physiological properties of trans fatty acids (TFA) with particular emphasis on conjugated linoleic acid isomers (CLA)-a review. Fett/Lipid 100, 190-210.

Freitsche, J. \& Steinhardt, H. (1998). Amounts of conjugated linoleic acid (CLA) in German foods and evalua tion of daily intake. Zeitschrift fur Lebeinsmitteluntersuchung und-forschung A 206(2), 77-82.

Freudenheim, J.L., Marshall, JR., Vena, J.E., Laughlin, R., Brasure, JR., Swanson, M.K., Nemoto, T. \& Gra ham, S. (1996). Premenopausal breast cancer risk and intake of vegetables, fruits, and related nutrients. 
Journal of National Cancer Institute 88(6), 340-8.

Gitane Fuke \& José Laerte Nornberg. (2017). Systematic evaluation on the effectiveness of conjugated linoleic acid in human health. Critical Reviews in Food Science and Nutrition 57(1), 1-7. Found at: https:// doi.org/10.1080/10408398.2012.716800. Accessed on $5^{\text {th }}$ October, 2018.

Gaullier, JM., Halse, J., Hoye, K., Kristiansen, K., Fafertun, H., Vik, H et al. (2005). Supplementation with conjugated linoleic acid for 24 months is well tolerated by and reduces body fat mass in healthy, over weight humans. Journal of Nutrition 135, 778-84. Accessed on $5^{\text {th }}$ October, 2018.

Glatthaar, BE., Horing, D.H. \& Moser, U. (1986). The role of ascorbic acid in carcinogenesis. Advances in Experimental Medical Biology 206, 357-77.

Griinari, JM., Chouinard, PY. \& Bauman, DE. (1997). Trans fatty acid hypothesis of milk fat depression re vised. In: Proc. Cornell Conf. Feed Manuf. Pages 208-216, Cornell University, Ithaca, NY.

Griswold, D.P. Jr., A. E. Casey, E.K. Weisburger \& Weisburger, J.H. (1968). The Carcinogenicity of Multiple Intragastric Doses of Aromatic and Heterocyclic Nitro or Amino Derivatives in Young Female Sprague -Dawley Rats. Cancer Research 28 (5), 924-933.

Grundker C., \& Emons, G. (2017). The role of gonadotropin-releasing hormone in cancer cell proliferation and metastasis. Front-endocrinol. (Lausanne) 8, 187. DOI: 10.3389/fendo 2017.00189.ecollection 2017.

Ha, YL., Grimm, NK. \& Pariza, MW. (1987). Anticarcinogens from fried ground beef: heat altered derivatives of linoleic acid. Carcinogenesis 8, 1881-7.

Harman, D. (1992). Role of free radicals in aging and disease. Ann NY Acad Sci. 67, 126-41.

Herzallah, S.M., Humeid, M.A. \& Al-Ismail, K.M. (2005). Effect of Heating and Processing Methods of Milk and Dairy Products on Conjugated Linoleic Acid and Trans Fatty Acid Isomer Content. Journal of Dairy Science 88(4), 1301-10. DOI: 10.3168/jds. Accessed on $14^{\text {th }}$ Dec. 2018.

Herzallah, S.M., Al-Ismail, K.M. \& Humeid, M.A. (2005). Influence of some heating and processing methods on fatty acid profile of milk and other dairy products. Journal of Food Agriculture and Environment 3 (1), 103-107.

Hoffmann, K., Blandszun, J., Brunken, C., Hopker, W., Tauber, R. \& Steinhart, H. (2005). Distribution of pol yunsaturatedf fatty acids including conjugated linoleic acids in total and subcellular fractions from healthy and cancerous parts of human kidneys. Lipids 40(3), 309-315.

Huang, G., Zhong. X., Cao, Y. \& Chen, Y. (2007). Antiproliferative effects of conjugated linoleic acid on hu man colon adenocarcinoma cell line Caco-2. Asia Pac J Clin Nutr. 16 Suppl 1, 432-6;

Ip, C., Scimeca, J. \& Thompson, H.J. (1994). Conjugated linoleic acid: a powerful anticarcinogen from animal fat sources. Cancer 74(3), 1050-1054.

Ip, C., Banni, S., Angioni, E., Carta, G., MacGinley, J., Thompson, HJ., Barbano, D. \& Bauman, D. (1999). Conjugated linoleic acid enriched butterfat alters mammary gland morphogenesis and reduces cancer risk in rats. Journal of Nutrition 129(12), 2135-2142. Found at https://doi.org/10.1093/jn/129.12.2135. Accessed on $26^{\text {th }}$ Nov 2018.

Ip Clement., Sou Fei Chin., Joseph A. Scimeca \& Michael W. Pariza. (1991). Mammary Cancer Prevention by Conjugated Dienoic Derivative of Linoleic Acid. Cancer Research 51(22), 6118-6124.

Jaudszus, A., Moeckel, P., Hamelmann, E. \& Jahreis, G. (2010). Trans 10, cis-12 CLA-caused lipodystro phy is associated with profound changes of fatty acid profiles of liver, white adipose tissue and erythro cytes in mice: possible link to tissue-specific alterations of fatty acid desaturation. Annals Nutr Metab. 57, 103-111. https://doi.org/10.1159/000319877. Accessed on $28^{\text {th }}$ November 2018.

Kishino S., Ogawa, J., Omura. Y., Matsumura, K. \& Shimizu S. (2002). Conjugated linoleic acid production from linoleic acid by lactic acid bacteria. J Am Oil Chem Soc. 70, 159-63. doi: 10.1007/s11746-0020451-4.

Khanal, R.C. \& Olson, K.C. (2004). Factors Affecting Conjugated Linoleic Acid (CLA) Content in Milk, Meat, and Egg: A Review. Pakistan Journal of Nutrition 3(2), 82-98, DOI: 10.3923/pjn.2004.82.98. Accessed on $14^{\text {th }}$ Oct 2018.

Kongo Marcelino, J., João Leite., Ana Borges \& Duarte Ponte. (2014). Source of Variation of Conjugated- 
Linoleic-Acid Contents in Dairy Products. Journal of Food Processing \& Technology 5, 404. doi:10.4172/2157-7110.1000404). Accessed on 10 ${ }^{\text {th }}$ Dec. 2018.

Kushi, L.H., Fee, R.M., Sellers, T.A., Zheng, W. \& Folsom, A.R. (1996). Intake of vitamins A, C, and E and postmenopausal breast cancer. The Iowa Women's Health Study. American Journal of Epidemiology 144(2), 165-74.

Larsson, S.C., Bergkvist, L. \& Wolk, A. (2009). Conjugated linoleic acid intake and breast cancer risk in a prospective Swedish Cohort of Swedish women. Am J Clin Nutr. 90(3), 556-60.

Larsson, S.C., Bergkvist, L. \& Wolk, A. (2005). High-fat dairy food and conjugated linoleic acid intakes in relation to colorectal cancer incidence in the Swedish Mammography Cohort. American Journal of Clinical Nutrition 82(4), 894-900.

Lea, A.J. (1966). Dietary factors associated with death rates from certain neoplasms in man. Lancet 2, 332-3.

Lin, J.K., Lin., CH, Ling., Y.C, Lin-Shian, S.Y. \& Juan, I.M. (1998). Survey of catechins, gallic acid and methylxanthines in green, oolong, puerh and black teas. J. Agric. Food Chem. 46, 3635-42.

Garcia-Lopez, S., Echeverria E., Tsui, I. \& Balch, B. (1994). Changes in the content of conjugated linoleic acid (CLA) in processed cheese during processing. Food Research International 27, 61-64.

Macouzet, M., Lee., B.H. \& Robert, N. (2009). Production of conjugated linoleic acid by probiotic Lactobacil lus acidophilus La-5. J. Appl. Microbiol. 106(6), 1886-91. doi: 10.1111/j.1365-2672.2009.04164x.

McCann, S.E., Ip, C., Ip, M.M., McGuire, M.K., Muti, P., Edge, S.B., Trevisan, M. \& Freudenheim, J.L. (2004). Dietary intake of conjugated linoleic acids and risk of premenopausal and postmenopausal breast cancer-Western New York Exposure and Breast Cancer Study (WEB study). Cancer Epidemiol. Biomar. Prev. 13(9), 1480-84.

Miller Aine., Catherine Stanton., John Murphy \& Rosaleen Devery. (2003). Conjugated linoleic acid (CLA)-enriched milk fat inhibits growth and modulates CLA-responsive biomarkers in MCF-7 and SW480 human cancer lines. British Journal of Nutrition 90, 877-885.

Ministry of Public Health and Sanitation and Ministry of Medical Services. (2013). National Cancer Control Strategy (2011-2016), Nairobi.

Ministry of Health. (2013). National Guidelines for Cancer Management in Kenya. August 2013, Nairobi.

Mushtaq, S., Heather Mangiapane, E. \& Hunter, K.A. (2010). Estimation of cis-9, trans-11 conjugated linoleic acid content in UK foods and assessment of dietary intake in a cohort of healthy adults. British J. of Nutrition 103(9), 1366-74. doi: 10.1017/S000711450999328X.

National Cancer Institute. 2003. What you need to know and what you can do. Found at: www.niehs.nih.gov/ health/materials/cancer/ and the environment 508.pdf. Accessed $11^{\text {th }}$ April 2019.

National Research Council (NRC). (1996). Carcinogens and anti-carcinogens in the Human diet. National Academy of Sciences, Washington, D. C.

Van Nieuwenhove Carina P., RUBÉN Oliszewski \& Silvia N. González. (2009). Fatty Acid Composition and Conjugated Linoleic acid content of cow and goat cheeses from North western Argentina. Journal of Food Quality 32, 303-314. DOI:

Nuernberg Karin, D. Dannenberg, G. Nuernberg, K. Ender, J. Voigt, N.D. Scollan, J.D. Wood, G.R. Nutec \& Richardson, R.I. (2005). Effect of a grass-based and a concentrate feeding system on meat quality char acteristics and fatty acid composition of longissimus muscle in different cattle breeds. Livestock Pro duction Science 94(1-2), 137-147.

Ogawa, J., Kishino, S., Ando, A., Sugimoto, S., Mihara, K., \& Shimizu, S. (1998). Production of conjugated fatty acids by lactic acid bacteria. J BioSci Bioeng. 206(2), 77-82.

Ogawa, J., Matsumura, K., Kishino, S., Omura, Y., \& Shimizu, S. (2001). Conjugated linoleic acid accumul tion via 10-hydroxy-12-octadecaenoic acid during microaerobic transformation of linoleic acid by Lac tobacillus acidophilus. Appl Environ Microbiol. 67(3), 1246-52.

Oliveira, RL., Ladeira, MM., Barbosa, MAAF., Assunção, DMP., Matsushita, M., Santos GT. et al. (2008). Conjugated linoleic acid and fatty acids profile in the muscle and fat layer of water buffalo steers fed different fat sources. Braz J Vet Anim Sci. 60, 169-78. 
Lobos-Ortega, I., Revilla, I., Gonzalez-Martin, MI., Hernandez-Herrero, JM., Vivar-Quintana et al. (2012). Conjugated linoleic acid contents in cheeses of different composition during six months ripening. Czech Journal of Food Science 30, 220-226.

O'Shea, M., Bassaganya-Riera, J \& Mohede, I.C.M. (2004). Immunomodulatory properties of conjugated lino leic acid. Am J Clin Nutr. 79, S1199-S1206.

Paganga, G., Miller, N., \& Rice-Evans, C.A. (1999). The polyphenolic content of fruit and vegetables and their antioxidant activities. What does a serving constitute? Free Radical Research 30(2), 153-62.

Papasani V. Subbaiah, Debajit Sircar, Buzulagu Aizezi, \& Evan Mintzer. (2010). Differential effects of conju gated linoleic acid isomers on the biophysical and biochemical properties of model membranes. Bio chim Biophys Acta 1798(3), 506-514. DOI: 10.1016/j.bbamem.2009.11.020. Accessed on $10^{\text {th }}$ Octo ber 2018.

Papasani V.Subbaiah, Ian G.Gould, Samanta Lal, \& Buzulagu Aizezi. (2011). Incorporation profiles of conju gated linoleic acid isomers in cell membranes and their positional distribution in phospholipids. Bio chimica et Biophysica Acta (BBA) 1811(1), 17-24.

Pariza, M.W., Ashoor, S.H., Chu, F.S. \& Lund, D.B. (1979). Effects of temperature and time on mutagen for mation in pan-fried hamburger. Cancer Lett 7, 63-9.

Pariza, M.W. \& Hargraves, W.A. (1985). A beef-derived mutagenesis modulator inhibits initiation of mouse epidermal tumors by 7,12-dimethylbenz[a]anthracene. Carcinogenesis 6, 591-3.

Pestana, J.M., Martins, S.I.V., Alfaia, C.M.M., Lopes, P.A., Costa ASH et al. (2009). Content and distribution of conjugated linoleic acid isomers in bovine milk, cheese and butter from Azores. Dairy Science Tech nology 89,193-200.

Proteggente, A.R., Pannala, A.S., Paganga, G., Van Buren, L., Wagner, E., Wiseman, S., Van De Put \& Weis burger, J.H. (1999). Mechanisms of action of antioxidants as exemplified in vegetables, tomatoes and tea. Food Chem. Toxicol. 37(9-10), 943-8.

Rahim Aydin. (2005). Conjugated Linoleic Acid: Chemical Structure, Sources and Biological Properties. Turkish J Veterinary and Animal Science 29, 189-205.

Risérus, U., Arner, P., Brismar, K. \& Vessby, B. (2002). Treatment with dietary trans10, cis12 conjugated lin oleic acid causes isomer-specific insulin resistance in obese men with the metabolic syndrome. Diabe tes Care 25(9), 1516-21.

Rizenthaler, KL., McGuire, MK., Falen, R., Schultz, TD., Dasgupta, N. \& McGuire, MA. (2001). Estimation of conjugated linoleic acid intake by written dietary assessment methodologies underestimate actual intake evaluated by food duplicate methodology. Journal of Nutrition 131(5), 1548-54.

Regula, A., Boncza, G. \& Pustowiak, H. (2005). The effect of heat treatment on the free fatty acids in ewe's milk. Biotechnology in Animal Husbandry 21, 237-240.

Ren, Y., Perez, T.I., Zuidhof, M.J., Renema, R.A. \& Wu, J. (2013). Oxidative stability of omega-3 polyunsatu rated fatty acids enriched eggs. J. Agric Food Chem. 61(47), 11595-602. doi: 10.1021/jf403039m. Ac cessed on $15^{\text {th }}$ Dec. 2018.

Rock, C.L., Jacob, R.A. \& Bowen, P.E. (1996). Update on biological characteristics of the Antioxidant micro nutrients- Vitamin C, Vitamin E and the carotenoids. J. Am. Diet. Assoc. 96, 693-702.

Pal Singh Jatinder, Amritpal Kaur,Khetan Shevkani, \& Narpinder Singh. (2016). Composition, bioactive com pounds and antioxidant activity of common Indian fruits and vegetables. J. Food Sci. Technol. 53(11), 4056-4066. DOI: 10.1007/s13197-016-2412-8.

Shantha, N.C., Decker, E.A. \& Ustunol, Z. (1992). Conjugated linoleic acid concentration in processed cheese. Journal of the American Oil Chemists' Society 69, 425-428.

Shokryazdan Parisa, Mohamed Ali Rajion, Goh Yong Meng, Liang Juan Boo, Mahdi Ebrahimi \& Maryam Royan. (2015). Conjugated linoleic acid: A potent fatty acid linked to animal and human health. Criti cal Reviews in Food Science and Nutrition 57(13), 2737-2748. Found at: https:// doi.org/10.1080/10408398.2015.1060190, Accessed on $25^{\text {th }}$ November 2018

Suksombat W., Samitayotin S. \& Lounglawan, F. (2006). Effects of conjugated linoleic acid supplementation in layer diet on fatty acid compositions of egg yolk and layer performances. Poultry Science 85(9), 
1603-1609. Accessed on $15^{\text {th }}$ Dec. 2018.

de Vrese, M. \& Schrezenmeir, J. (2008). Probiotics, prebiotics, and synbiotics. Adv Biochem Eng Biotechnol. 111, 1-66. DOI: 10.1007/10_2008_097.

Tao Wang \& Hong Gu Lee. (2013). Advances in Research on cis-9, trans-11 Conjugated Linoleic Acid: A Major Functional Conjugated Linoleic Acid Isomer. Critical Reviews in Food Science and Nutrition 55 (5), $720-731$.

J van Wijlen. (2011). Long-term conjugated linoleic acid supplementation in humans-effects on body composi tion and safety. European J. of Lipid Science and Technology 113(9), 1077-94. Found at: https:// doi.org/10.1080/10408398.2012.674071. Accessed on 25th November 2018.

WHO. 2018. Cancer key facts. Found at https://www.who.int/news-room/fact-sheets/detail/cancer. Updated 12 September, 2018. Accessed on $31^{\text {st }}$ December, 2018.

Yamasaki, M., Kishihara, K., Mansho, K., Ogino, Y., Kasai, M., Sugano, M., Tachibana, H \& Yamada, K. (2000). Dietary conjugated linoleic acid increases immunoglobulin productivity of Sprague-Dawley rat spleen lymphocytes. Biosci Biotechnol Biochem. 64, 2159-2164. 